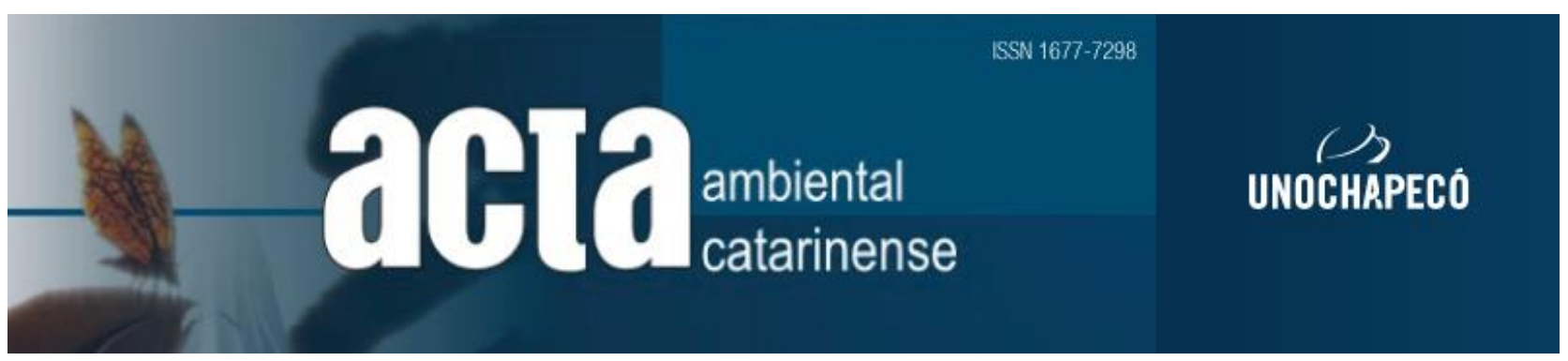

\title{
USO DO GEOPROCESSAMENTO PARA MAPEAMENTO DO USO E OCUPAÇÃO DO SOLO COM ÊNFASE EM MÉTRICAS DA PAISAGEM: UM ESTUDO DE CASO NA BACIA HIDROGRÁFICA DO RIO ÁGUA BRANCA.
}

\author{
Lorena Souza da Silva ${ }^{1}$ \\ Mauricio Santana Moreau ${ }^{2}$ \\ Ubirathan Santos Daltro ${ }^{3}$
}

\begin{abstract}
Resumo
A bacia hidrográfica do Rio Água Branca que assim como outras bacias tem sofrido alterações de origem antrópica, como desmatamento de matas ciliares, poluição dos rios e modificações na paisagem. Estes impactos podem variar de acordo com o uso e cobertura do solo e podem ser mitigados ou melhor ordenados com o uso do geoprocessamento. Neste sentido, a presente pesquisa objetivou mapear a cobertura do solo na bacia, utilizando imagens disponibilizadas gratuitamente pelo software TerraIcognita referentes ao ano de 2018 e processadas em ambiente SIG. Utilizou-se neste trabalho a classificação supervisionada das imagens, que possibilitou analisar a condição dos fragmentos florestais através das métricas da paisagem, esta metodologia também tornou possível a delimitação das áreas de preservação permanente juntamente a legislação vigente. Os métodos usados permitiram chegar nos seguintes resultados: caracterização da cobertura da bacia hidrográfica, onde a vegetação está disposta a paisagem como fragmentos, totalizando 8 fragmentos, variando entre 214 ha e 75 ha, que sob o ponto de vista da ecologia da paisagem representa matriz da paisagem, mas possui pequenos fragmentos altamente expostos as pressões do meio, bem como o uso conflitante de áreas destinadas à preservação.
\end{abstract}

Palavras-chave: Geotecnologias, fragmentação florestal, áreas de preservação.

\begin{abstract}
The Água Branca River Basin, as well as other basins, has been suffering anthropic alterations, such as deforestation of gallery forests, river pollution and changes in the landscape. These impacts may vary depending on the use and cover of the soil and can be reduced or better sorted through the use

\footnotetext{
${ }^{1}$ Mestranda em Ciências Ambientais na Universidade Estadual do Sudoeste da Bahia - UESB-

E-mail: loriesouza@hotmail.com

2 Doutor em Solos e Nutrição de Plantas - UESC/BA - Professor da Pós-graduação - FTC/BA. E-mail: mmoreau@uesc.br

${ }^{3}$ Engenheiro Ambiental-FTC/BA.E-mail: bira_sd@hotmail.com
} 
of geoprocessing. Therefore, the present research aimed at mapping the soil cover in the basin, using images, dated from the year 2018, made available for free by TerraIcognita software and processed in a GIS environment. In this project the supervised image classification was used, which made it possible to analyze the forest fragments through landscape metrics. This methodology also made possible the delimitation of the areas of permanent preservation associated with the current legislation. The methods that were used allowed us to achieve the following results: characterization of the basin's cover, where the vegetation is placed on the landscape as fragments, totaling 8 fragments, that varies between 214 ha and 75 ha, which, from the point of view of the landscape ecology, represents the landscape matrix but has small fragments highly exposed to the environmental pressures, as well as the conflicting use of areas designated for preservation.

Keywords: geotechnologies, forest fragments, preservation areas.

\section{MAPEAMENTO COM ÊNFASE EM MÉTRICAS DA PAISAGEM NA BHRA.}

\section{INTRODUÇÃ̃o}

As bacias hidrográficas são sistemas socioecológicos complexos, devido ao conjunto de interações antrópicas e naturais que ocorrem em seu perímetro (VIANA; MORAES, 2016). Atualmente, o aumento da sua complexidade tem sido agravada pelo uso desordenado do espaço, alterando as relações ecológicas e serviços por ela prestados.

Esse ordenamento ambiental pode ser concebido pela estruturação de espaços em bacias hidrográficas, que são consideradas unidades de gestão territorial, de acordo com o Plano Nacional de Recursos Hídricos. Aderir a bacias hidrográficas como unidades de ordenamento territorial é uma ideia concebida por diversos autores (BEHERA e PANDA, 2006; QUEIROZ et al.2014; AHER et al., 2014; ARAÚJO et al., 2015).

A Bacia Hidrográfica do Rio Água Branca (BHRAB), que assim como outras bacias tem sofrido pressões antrópicas, apresenta características distintas e alteradas da sua forma original, como poluição dos rios, desmatamento de matas ciliares, degradação dos solos e acréscimo de estruturas urbanas. Estes aspectos devem estar inseridos na discussão de ordenamento territorial, visto que ele abastece parte da população do município de Itabuna-Bahia.
Considerando as alterações sofridas pela BHRAB e o seu percentual cada vez menor de matas ciliares, são necessárias estratégias de recuperação de áreas de preservação permanente, áreas protegidas de acordo com o Código Florestal Brasileiro, visto que a fragmentação dos remanescentes de vegetação nativa em uma bacia hidrográfica contribui para intensificação de processos erosivos e da diminuição da quantidade e qualidade da água (AZEVEDO; GOMES; MORAES, 2016; CAMPOS et al., 2016).

Diante do exposto enfatiza-se que o estudo de áreas fragmentadas é fundamental, visto que permite o estabelecimento de modelos de conservação e preservação biológica, por definir um grau de comprometimento espacial e ecológico da área em análise. Estas mudanças podem ser analisadas por díspares pontos da Ecologia da Paisagem, a fim de assegurar a manutenção da estrutura e dos processos fundamentais para a conservação da qualidade ambiental.

Atualmente, a metodologia mais utilizada pela Ecologia da Paisagem, são as métricas de paisagem, modelos matemáticos que estão relacionadas a estrutura da paisagem e correlacionadas com processos ecológicos, segundo Lang e Blaschke (2009). Sendo assim, a presente pesquisa objetivou avaliar a condição dos remanescentes florestais 
inseridos na bacia hidrográfica do Rio Água Branca no município de Itabuna-Bahia e o uso e ocupação do solo segundo os usos preponderantes instituídos pelo Código Florestal Brasileiro ( Lei 12.651/2012)

\section{Material e Métodos}

\section{1 Área de Estudo}

A área de estudo localiza-se no município de Itabuna, mesorregião sul do estado da Bahia, Brasil. A bacia hidrográfica do Rio Água Branca compreende as coordenadas 471097 e 465784 Sul e longitudes 8368029 e 8366622 Oeste, Datum SIRGAS 2000, zona 24S, abrangendo uma área de 21,47 km2, conforme figura 1 .

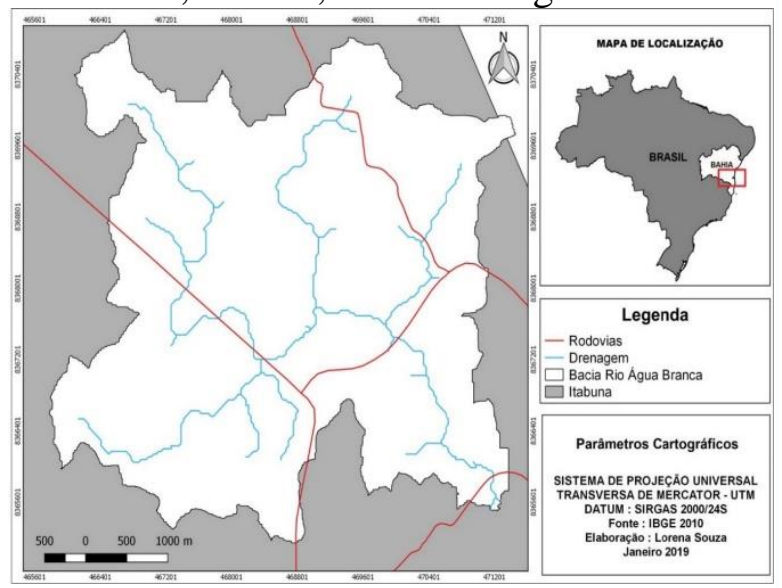

Figura 1. Mapa de Localização da Área de Estudo.

A bacia é composta pelos bairros Nossa Senhora das Graças, Jardim Grapiúna, Corbiniano Freire, Novo Horizonte, São Roque, Monte Cristo, Nossa Senhora de Fátima, Nova Califórnia e uma pequena parte dos bairros Alto do Maron e Califónia.

A população da cidade de Itabuna- $\mathrm{Ba}$ foi estimada no ano de 2018 em 212.740 habitantes, estando entre os trinta municípios mais populosos do nordeste do Brasil (IBGE, 2018). O perímetro urbano do município aloca grande parte da população, cerca de $97,6 \%$, o que reflete na ocupação na bacia hidrográfica que engloba 10 bairros da zona urbana.
De acordo com a classificação internacional de Köppen, esta região apresenta clima do tipo Af , Clima equatorial (PMI, 2016). O clima Af caracterizado por valores médios de temperatura de $240 \mathrm{C}$, e médias de precipitação acima de $2.000 \mathrm{~mm}$ por ano. Caracteriza-se como clima tropical úmido, com inverno pouco rigoroso e médias de precipitação anual altas, com ausência de estações de seca.

\subsection{Procedimentos}

A metodologia utilizada para desenvolver o presente estudo consiste em uma pesquisa exploratório-descritiva, a qual utiliza como procedimento técnicas padronizadas para coleta de dados sob uma visão sistemática. Tal pesquisa observa os dados, registra, interpreta de modo que possibilite umas novas percepções sobre o objeto de estudo, viabilizando seu conceito e delimitação (PRODANOV, 2013). Quanto a natureza da pesquisa, foi utilizada uma abordagem quantitativa. Segundo Mattar (2001), a pesquisa de caráter qualitativo busca o aprofundamento das investigações, através da validação de hipóteses utilizando-se de dados estruturados. Ela quantifica os dados e generaliza os resultados.

Inicialmente para efetuar a presente pesquisa, foi realizada uma pesquisa bibliográfica utilizando-se de livros, teses, dissertações, artigos, etc. Para extração das informações básicas, tais como principais vias de acesso, ferrovias, rede de drenagem principal, limites municipais, foram utilizados os shapes disponibilizados pelo IBGE. Para as informações referentes à cobertura vegetal e uso das terras foram utilizadas as imagens digitais do satélite Landsat 8, disponibilizadas pelo software livre TerraIncognita com resolução espacial de $30 \mathrm{~m}$, as quais foram trabalhadas em escala 1:60.000.

Para os mapas de declividade e rede de drenagem, foram utilizados as imagens srtm disponibilizadas gratuitamente pelo site TOPODATA, as folhas utilizadas possuem as numerações 14_405 e 14_39.Todo o 
processamento de dados foi realizado pelo software QuantumGis 2.18.24.

\subsection{Procedimentos Analíticos}

\subsubsection{Mapeamento do uso e ocupação do solo} da Área de Estudo

O mapeamento da vegetação de Mata Atlântica da bacia hidrográfica em questão foi realizado através de etapas distintas: aquisição, processamento de imagens $\mathrm{e}$ aplicação de metodologia de análise. A forma de entrada de dados foi feita via importação de camadas raster (inserção de imagens),ortofotomosaico do ano de 2018 disponibilizado pelo TerraIcognita. Neste sentido o Ortofotomosaico é constituído de imagens de alta qualidade, que são muito úteis para a identificação e mapeamento de feições geográficas e do uso do solo como fragmentos florestais, corpos d’água, afloramentos rochosos, etc.

Para identificação das áreas de vegetação, foi utilizado o processo de classificação a partir do algoritmo de máxima verossimilhança, que é intrínseco ao método de classificação supervisionada. Foram utilizadas 12 amostras para cada classe de mapeamento (mata/cacau, pastagem, área urbana e superfície aquática). Além da análise dos dados através do software, foi necessário reconhecer a área de estudo, através de visitas técnicas para delimitação das feições. Para este estudo foram considerados apenas quatro classes de uso e ocupação que possuem maior representatividade. Para a delimitação do perímetro da bacia e rede de drenagem, foi gerado o modelo digital de elevação do terreno - MDE, obtido das folhas SRTM. Após a elaboração do modelo, utilizou-se a função r.watershed do software para delimitar o perímetro e a rede de drenagem da bacia, conforme metodologia proposta por Fan et.al,2013 que consiste no preenchimento das regiões espúrias e posterior aplicação do método D8 (Eight Direction Pour Point Model), para este estudo foi utilizado uma área mínima de 1000 células. Todos os procedimentos foram realizados utilizando o software QuantumGis 2.18.24

\subsubsection{Análise da paisagem utilizando métricas da Paisagem \\ O mapa de fragmentos florestais foi} obtido através do mapa de uso e ocupação do solo. Resultando na criação de arquivos vetoriais poligonais da composição florestal da área de estudo. Os fragmentos foram examinados com base no mapa de fragmentos florestais. Para análise dos índices de ecologia da paisagem foram aplicadas as seguintes Métrica de Área, Perímetro, Borda e Forma.

As métricas foram computadas no ambiente SIG, através da ferramenta Calculadora de Campo. Para aplicação das métricas de Área (CA) referente ao somatório das áreas de todas os fragmentos da classe em estudo e Perímetro, referente a linha que delimita a região,foram utilizados os modelos matemáticos propostos por FORMAN \& GORDON (1986), também conhecidas como métricas base, servem de subsidio para toda aplicação do estudo.

As métricas de borda, foram representadas pela soma do perímetro do total de bordas e pela densidade relativa de borda em relação a área de estudo. Para Aplicação das métricas de paisagem denominadas Índices de Forma (MI) interior/borda, utilizou-se a seguinte fórmula: $\mathrm{Mi}=\mathrm{P} / \mathrm{A}$, onde Mi é um índice de forma da mancha i, $\mathrm{P}$ é o seu perímetro em quilômetros e A corresponde a sua área em quilômetros quadrados , conforme (BOWEN; BURGESS, 1981).

\subsubsection{Mapas de Áreas de Preservação e Mapa de Conflitos de usos.}

O procedimento para a delimitação das áreas de preservação permanente foi efetuado ao longo de cursos d'água e nascentes, através da aplicação da ferramenta "buffer" de $100 \mathrm{~m}$ e $50 \mathrm{~m}$ respectivamente. Estes valores respeitam os limites fundados na Resolução Conama n³03/2002 
(BRASIL,2002). Para o Mapa de declividade, realizou-se processamentos para obtenção do modelo digital de elevação do terreno, os quais foram categorizados conforme metodologia de Barberi et al 2012. Após a delineamento das áreas de preservação, foi realizada a sobreposição destas áreas sob o mapa de uso e ocupação do solo, para identificar as áreas de uso irregular.

\section{ReSUltados E DiscuSSÃo}

\subsection{Mapeamento do uso e cobertura da terra}

O mapeamento de uso e ocupação do solo da Bacia Hidrográfica do Rio água Branca na escala 1:33.000 referente ao ano 2018 pode ser observado na figura 2 , e os valores das áreas são contabilizadas na tabela 1 .

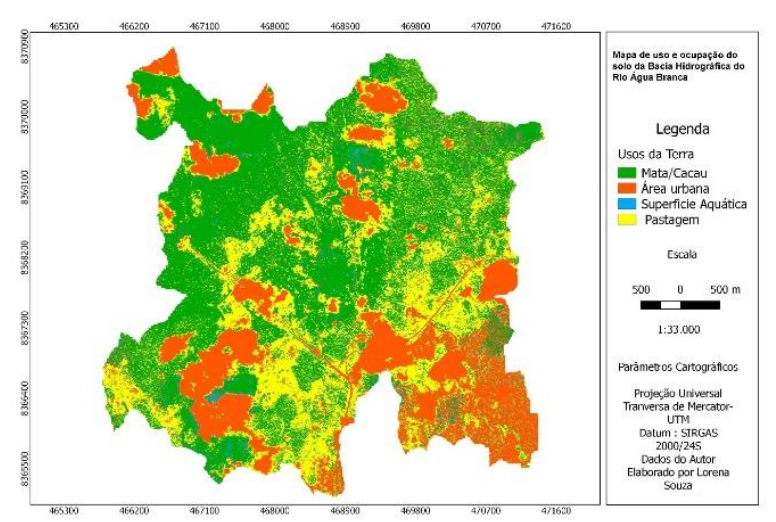

Figura 2. Mapa de Uso e Ocupação do Solo da Bacia Hidrográfica do Rio Água branca.

Tabela 1. Área das Classes de uso e cobertura na Bacia Hidrográfica do Rio Água Branca.

\begin{tabular}{c|c|c}
\hline Classe & Área (ha) & Porcentagem (\%) \\
\hline Área Urbana & 518,332 & $24,17 \%$ \\
\hline Mata/Cacau & 989,233 & $46,12 \%$ \\
\hline Pasto & 597,099 & $27,84 \%$ \\
\hline Superfície Aquática & 40,164 & $1,87 \%$ \\
\hline \multicolumn{2}{l}{ Fonte: Dados do Autor (2019). }
\end{tabular}

Em análise ao uso e ocupação do solo, foram identificados 4 classes de uso da terra, mata/cacau, pastagem, área urbana $\mathrm{e}$ superfície aquática. Em observância aos dados, pode-se inferir que a classe Mata/cacau apresenta maior área (ha) na paisagem, com pequenas áreas fragmentadas, somando 989,233 ha o que corresponde a $46,12 \%$ da área de estudo. Por apresentar maior área sob os demais elementos, a classe mata/cacau pode ser considerada a matriz da paisagem por apresentar maior conectividade e maior influência sob dos demais componentes paisagísticos.

Logo em seguida, e notoriamente a Classe Pasto apresenta-se como a de maior expressão, representando $27,84 \%$ da área. Segundo Louzada (2008) esta cobertura quando bem manejada proporciona recobrimento vegetal por todo ano, impedindo a velocidade de escorrimento superficial quando comparado a outras culturas que deixam o solo exposto durante o preparo para o plantio. As demais classes são minoritárias e simbolizam: área urbana, solo exposto e superfície aquática, sendo as duas primeiras anteriormente citadas, classes de origem antrópica que podem trazer situações adversas para a conservação e restauração dos fragmentos florestais. Em suma foram especializadas conforme a figura $2 \mathrm{e}$ quantificadas de acordo a descrição da tabela 1.

Em uma análise mais detalhada da ocupação da área de estudo, têm-se a categoria denominada como mata/cacau para caracterizar uma vegetação típica da Mata Atlântica em diversos estágios regeneração. Ainda é marcada pela presença de áreas de plantio em sistemas agroflorestais (SAFs), uma associação de Mata Atlântica com cultivo de cacau entre outros. Os SAFs têm exercido uma enorme importância na microbacia em questão, uma vez que a utilização desses sistemas permitem atenuar o processo de fragmentação (SOLLBERG, 2014), diminuindo a necessidade de abertura de novas áreas para cultivo. No entanto, essa classe tem sofrido expressivas alterações ao longo do tempo, por processos que são evidenciados nas demais classes, como por 
Silva et al.,

exemplo, o mapeamento das áreas de pastagens, mostra a remoção da cobertura arbóreo-arbustiva para implantação destas atividades.

A classe que também evidencia as interferências diretas na área da bacia hidrográfica é a categoria área urbana, que é o maior agente transformador do perímetro estudado, com uma representatividade de $24,17 \%$, é marcada pela presença de construções irregulares, a formação dos bairros adjacentes foi em sua maioria por meio de "invasões" o que acarreta um desordenamento territorial, problemas de infraestrutura e gestão de resíduos, que são significativos em toda área da BHRAB.

\subsection{Análise dos índices de paisagem}

O mapeamento possibilitou contabilizar 8 fragmentos florestais em toda a área representativa da BHRA. O detalhamento das métricas utilizadas neste estudo, juntamente com suas siglas e significados é descrito na tabela 2 e figura 3.

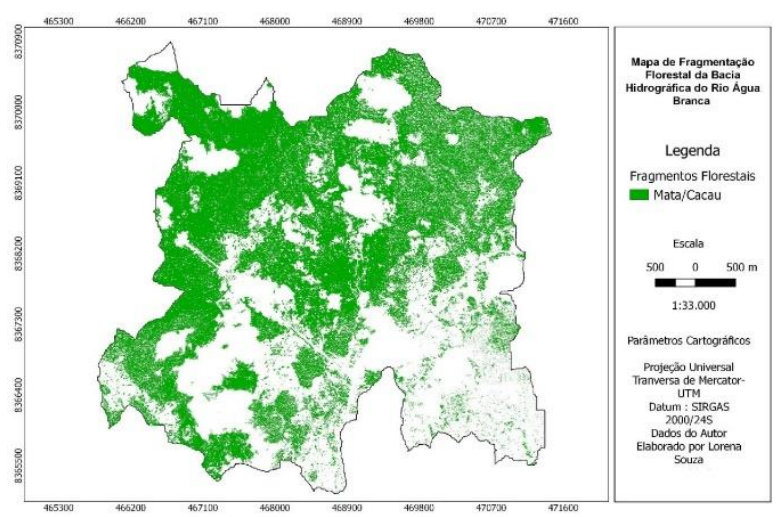

Figura 3. Mapa da Fragmentação Florestal do Rio Água branca.

Tabela 2. Índices da Ecologia da Paisagem calculados para a bacia hidrográfica do Rio Água Branca.

\begin{tabular}{c|c|c|c|c}
\cline { 2 - 5 } \multicolumn{1}{c|}{} & Tamanho & Forma & Perímetro & Borda \\
\hline NumP & CA & MSI & - & TEM \\
\hline 1 & 104,682 & 1,372 & 143,675 & 143,675 \\
\hline 2 & 101,358 & 2,110 & 213,876 & 213,876 \\
\hline 3 & 78,445 & 10,703 & 839,67 & 839,67 \\
\hline 4 & 75,121 & 7,253 & 544,87 & 544,87 \\
\hline 5 & 85,286 & 11,471 & 978,325 & 978,325 \\
\hline 6 & 207,965 & 1,002 & 208,45 & 208,45 \\
\hline 7 & 121,796 & 1,515 & 184,56 & 184,56 \\
\hline 8 & 214,575 & 1,394 & 299,23 & 299,23 \\
\hline Total & 989,233 & 36,823 & $3.412,656$ & $3.412,656$ \\
\hline
\end{tabular}

*Nump- Número de fragmentos (Adimensional); CAÁrea da classe (ha);MSI-Média do índice de forma (Adimensional); - Perímetro dos fragmentos $\left(\mathrm{km}^{2}\right)$; TEM- Área de borda dos fragmentos $\left(\mathrm{km}^{2}\right)$;

Em análise aos fragmentos florestais da área de estudo do ponto de vista da ecologia da paisagem, que serviram para uma caracterização geral dos fragmentos, têm se que: os fragmentos possuem pouca oscilação de pequenos á grandes; em comparação aos valores encontrados, os fragmentos que possuem valores "médios" consideráveis quanto ao tamanho. Para McGarigal et al (1994) o tamanho médio dos fragmentos é um bom indicativo do grau de rompimentos de áreas anteriormente contínuas, visto que é função do número de fragmentos e área total ocupada pela classe. Sendo assim, paisagens que apresentam os menores valores de tamanho médio para fragmentos devem ser vistas como mais fragmentadas.

O maior fragmento localizado na área de estudo possui 214,575 ha, seguido do fragmento intitulado 6 na tabela com 207,965 ha. Os demais fragmentos possuem valores médios quanto á sua dimensão, sendo que os menores fragmentos ocupam uma área 75,121 a 85,286 ha. Sendo os principais representantes das manchas ou patches, que são os menores elementos observáveis na 
paisagem. Juntos somam 238,852ha e correspondem a $\mathrm{x} \%$ da área de estudo.

Os valores anteriormente citados estão inseridos nas métricas de área que são consideradas como índices de "alicerce" para o conhecimento da paisagem. Através destas é possível calcular outras métricas que são úteis para estudos ecológicos, visto que a riqueza e permanência de algumas espécies dependem de espaços mínimos viáveis para sua existência (VOLOTÃO,1998).

Quanto a sua localização e disposição territorial, os fragmentos identificados foram mapeados e dispostos em escala 1:33.000, conforme a imagem a seguir:

Para Forman e Godron (1986), os grandes fragmentos são importantes para manutenção da diversidade biológica e de processos ecossistêmicos em larga escala. Entretanto, os fragmentos menores também desempenham papel importante na paisagem, podendo funcionar como elementos de ligação, trampolins ecológicos (stteping stones) entre grandes áreas, garantir e aumentar o nível de heterogeneidade da matriz e atuar como abrigo de espécies que requerem ambientes particulares e que só ocorrem nessas áreas especificas. Com base nisso, deve-se evidenciar que os pequenos remanescentes merecem atenção especial, por estarem altamente expostos as pressões antrópicas, além de correr sérios riscos de serem extintos ao longos dos anos, se não forem adotadas medidas de conservação e manejo que possibilitem uma interligação a fragmentos maiores e/ou o aumento da sua própria área.

Para Pirovani et al 2014, os fragmentos de áreas pequenas apresentam vulnerabilidade aos padrões de sustentabilidade ao passar dos anos. Evidenciando ainda que os remanescentes florestais podem ser na realidade, núcleos de colonização de florestas secundárias.

A métrica de forma obtida pela proporção simples da área e perímetro, permite avaliar os fragmentos como regulares ou irregulares. Valores próximos de 1 indicam que maior regularidade quanto à forma, sendo fragmentos mais circulares e pode ter o seu interior mais protegido e conservado. Enquanto que valores mais distante de 1 caracterizam fragmentos mais alongados, mais suscetíveis ao efeito de borda e maior grau de perturbação.

Interpretando os dados obtidos é possível perceber que os remanescentes florestais com maior valor de área possuem valores de índice de forma mais próximo a 1 enquanto os fragmentos menores possuem valores mais distantes. Em uma avaliação geral, todos os fragmentos apresentaram valores próximos a 1, com exceção dos fragmentos menores, indicando fragmentos irregulares, isso se deve a proporção de bordas (apontando fragmentos muito recortados), com alta razão de perímetro e área, sendo esperado que apresentem uma menor razão.

Foi observado que o tamanho e a forma dos remanescentes estão intrinsecamente ligados à borda, pois quanto mais regulares, mais longínquos da borda, mantendo a área central distante de fatores externos. Já os irregulares, farão com que haja maior interação com a matriz (sendo maior a proporção de bordas), o que, com o tempo, irá influenciar na qualidade e estrutura desses ecossistemas (PIROVANI et al, 2014)

Entretanto, mesmo possuindo formatos mais irregulares, os fragmentos maiores tem o efeito de borda compensado. Por exemplo, quanto maior o índice de forma maior a irregularidade do fragmento, mas se a área do fragmento é pequena todo o fragmento estará sob efeito de borda. Enquanto que os fragmentos maiores, apesar de apresentarem valor elevado para o MSI, irregularidade quanto ao tamanho e também estarem suscetíveis ao efeito de borda, possuem uma maior área que é condição ideal para a conservação do fragmento mediante a sobrevivência e permanência de espécies (OLIVEIRA, 2011).

Smaniotto (2007) ressalta que esta métrica serve como uma ferramenta de planejamento e gestão regional, visto que 
fragmentos alongados podem ser utilizados para estabelecer corredores ecológicos, que garantem a conectividade florestal, fluxo gênico de matéria e o deslocamento da fauna.

Quanto as métricas de borda, o total de bordas (TEM), é dado pela soma do perímetro de todos os fragmentos (sendo neste trabalho o valor de perímetro de cada fragmento). Sendo assim, fragmentos maiores apresentaram valores de borda e paralelamente fragmentos pequenos apresentam borda menores.

Em respeito à conectividade da área de estudo, foi medida após a aplicação de buffer (expansão de bordas) de 20,40,60 e 120m. O buffer de $20 \mathrm{~m}$ não possibilitou a conexão entre nenhum fragmento, sendo que a ferramenta quando aplicada a $40 \mathrm{~m}$ e $60 \mathrm{~m}$ obteve uma boa conectividade da paisagem com exceção da ligação de 2 e 1 fragmento respectivamente. A paisagem só esteve totalmente ligada com a aplicação do buffer de $120 \mathrm{~m}$. Visualizar a progressão da paisagem é considerável para manter a paisagem unida e consequentemente preservar os processos ecológicos e deslocamento de espécies presentes.

\subsection{Delimitação das áreas de preservação e conflitos de uso e ocupação do solo}

A delimitação de áreas de preservação permanente, tendo como base a Resolução Conama $\mathrm{n}^{\circ} .303$ possibilitou quantificar $\mathrm{e}$ categorizar as Apps em: APP 1 - Nascentes e suas respectivas áreas de contribuição e APP 2 - Ao longo das margens dos cursos d'água.

A App 1 rotulada como área de preservação permanente de nascentes, de acordo com a tabela 3 e figura 4, ocupa uma área equivalente a 14,48 ha, relativamente pequena o que significa possuir $0,67 \%$ da área de estudo. Segundo a legislação estadual, estas áreas devem ser protegidas com um raio de $50 \mathrm{~m}$ de vegetação, a fim de garantir o abastecimento hídrico da região, pois as nascentes são os afloramentos de lençóis subterrâneos que asseguram a recarga de rios.

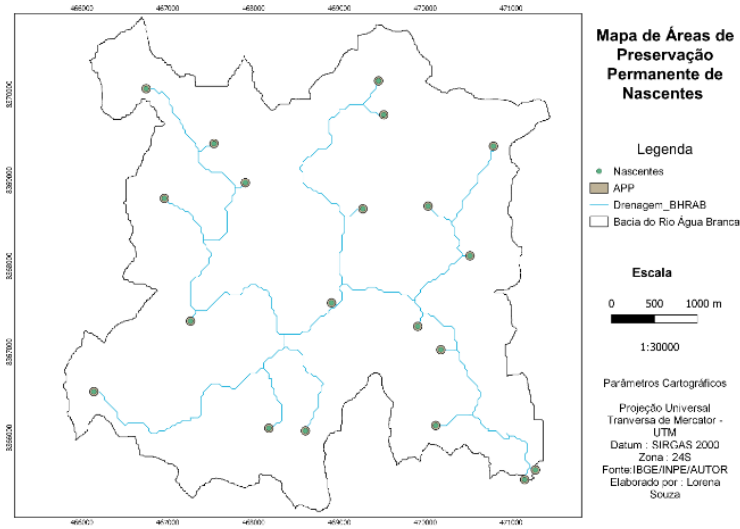

Figura 4. Mapa das Áreas de Preservação Permanente das nascentes da área de estudo.

Tabela 3. Quantificação das áreas de uso e cobertura da terra nas APPs de cursos dágua e nascentes na Bacia hidrográfica do Rio Água Branca.

\begin{tabular}{cccccc}
\hline Classes de Uso da Terra & $\begin{array}{c}\text { App 1 } \\
\text { App 2 }\end{array}$ \\
\cline { 2 - 5 } & Área em ha & $\mathbf{\%}$ & Área em ha & $\mathbf{\%}$ \\
\hline Mata/Cacau & 5,81 & 40 & 178,25 & 42 \\
\hline Área Urbana & 3,43 & 24 & 87,86 & 20 \\
\hline Superfície Aquática & 0,20 & 1 & 7,23 & 2 \\
\hline Pastagem & 5,04 & 35 & 156,00 & 36 \\
\hline TOTAL & $\mathbf{1 4 , 4 8}$ & $\mathbf{1 0 0}$ & $\mathbf{4 2 9 , 3 4}$ & $\mathbf{1 0 0}$ \\
\hline Fonte: Dados do Autor (2019). & & & &
\end{tabular}

Quanto a App 2 - Referente as áreas adjacentes aos cursos d água ocupa uma área de 483,411ha (conforme figura 5). Sabe-se da importância da conservação dessa faixa arbórea, pois conforme Casatti 2010, qualquer diminuição nas áreas ripárias pode ocasionar uma série de desequilíbrios, como por exemplo, a erosão do solo, entrada e saída de material orgânico e inorgânico que culminaria numa alteração em todo sistema aquático. 


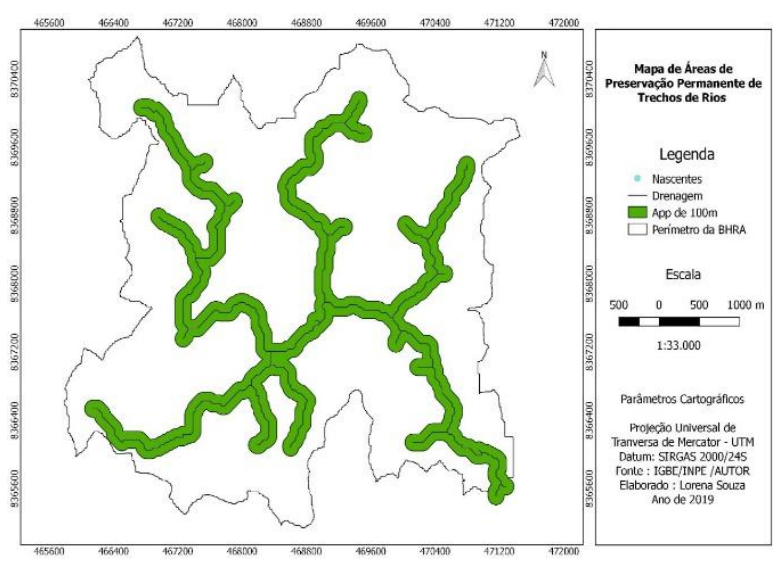

Figura 5. Mapa das Áreas de Preservação Permanente da área de estudo.

Do ponto de vista ecológico, diversos autores documentam a importância de manter as zonas ripárias na paisagem, segundo Metzger (2010), a largura desses corredores com vegetação interfere diretamente na qualidade do habitat protegido, visto que regulam o conjunto de áreas impactadas por efeitos de perturbação de borda e alterações microclimáticas; consequências anteriormente expostas na análise de fragmentação da área de estudo.

Em análise aos conflitos de uso e ocupação do solo e áreas destinadas a preservação, pôde-se observar o uso inadequado de $68,24 \%$ da áreas destinadas a proteção conforme legislação vigente. Os usos podem ser observados conforme a figura 6 abaixo e o detalhamento destas áreas é dado na tabela 3 .

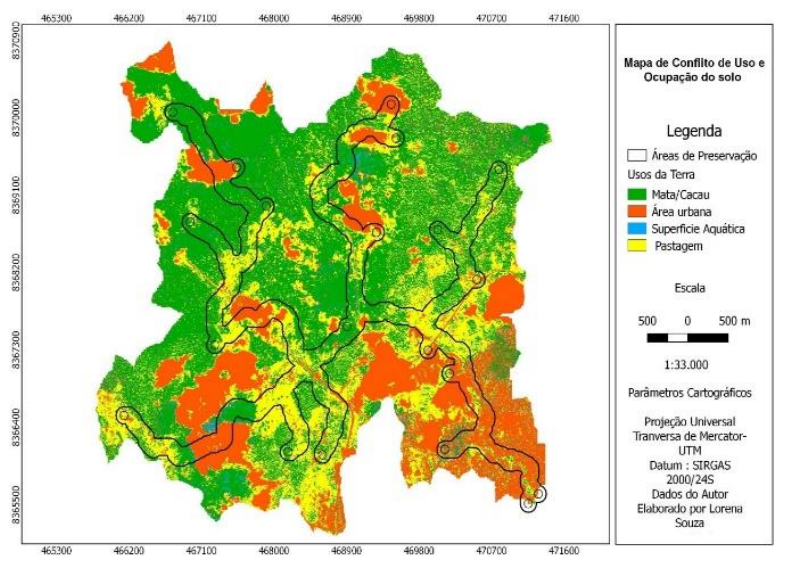

Figura 6. Mapa de Conflitos de usos com as áreas de preservação.

A App1 referente as áreas adjacentes as nascentes possui 14,48 ha. Verificou-se que $59 \%$ destas áreas estão ocupadas inadequadamente por áreas antropizadas e atividades de pastagens, o que pode ocasionar compactação e erosão do solo, causando assoreamento nos leitos dos rios. Além de ser fontes pontuais de poluição, visto que os pontos urbanos são responsáveis pelos lançamentos de efluentes não tratados.

Quanto as Apps 2 que descrevem as áreas adjacentes ao cursos d'água, conforme tabela anterior e figura 6 , possuem 429,34 ha o que configura uma considerável representatividade na área de estudo com $20,02 \%$ da área total da bacia hidrográfica. Em respeito aos aspectos físicos, $42 \%$ são ocupadas por matas/cacau, muitas vezes sob forma de fragmentos florestais e $2 \%$ por superfícies aquáticas. A segunda maior expressão das Apps 2 são compostas por pastagens e somam 156ha (36\% da área). De forma geral, $56 \%$ das áreas destinadas a proteção possuem ocupações irregulares.

Do ponto de vista geral, 443,82 ha de área que deveriam ser de uso exclusivo de preservação apenas 191,49ha são efetivamente de áreas vegetadas e superfícies aquáticas. Outro aspecto importante é que dentro deste percentual de $42 \%$ de áreas que apresentam vegetação, estão dispostas na paisagem muitas vezes como fragmentos florestais, com tamanhos e formas irregulares, o que significa dizer áreas altamente expostas as pressões do meio, sob desequilíbrio de algumas funções ecológicas.

Mediante aos resultados apresentados na área de estudo, algumas medidas podem ser recomendadas para garantir um melhor ordenamento territorial, conforme Louzada (2008) priorizando as áreas de conservação, através de medidas de controle e prevenção, tais como:a recuperação da vegetação da bacia hidrográfica através de práticas de reflorestamento e ressemeio, inspeção mais 
assídua dos órgãos ambientais, com intuito de autuar possíveis infratores em decorrência de ocupações irregulares, programas de educação ambiental para conscientização da população, criação de sistema que possibilite a implantação de projetos de ordenamento territorial, proteção e conservação da bacia.

\section{CONSIDERAÇões Finais}

A metodologia utilizada para delimitação automática da bacia mostrou-se satisfatória para visualizar os usos da terra, produzindo informações quantitativoespaciais. No entanto, ressalta-se a necessidade do emprego de técnicas mais avançadas em geoprocessamento que culminariam em resultados mais precisos e eficazes, devido a importância de estudos em áreas de bacias hidrográficas, que são tidas como instrumentos de planejamento territorial.

Do ponto de vista ecológico, as métricas mostraram algumas áreas altamente irregulares e expostas as pressões antrópicas, mas que de forma geral apresentam, em sua maioria, fragmentos com grandes áreas de cobertura florestal, sendo ainda a classe com maior representatividade da bacia.

O uso irregular das áreas adjacentes aos rios bem como nascentes podem acarretar em problemas ecológicos e afetar diretamente na qualidade da água. Demostrando a necessidade de implantar políticas públicas que efetivamente resguardem estas áreas.

\section{REFERÊNCIAS}

AHER, P. D.; ADINARAYANA, J.; GORANTIWAR S. D. Quantification of morphometric characterization and prioritization for management planning in semi-arid tropics of India: A remote sensing and GIS approach.Journal of Hydrology, v. 511, p. 850-860, 2014.
ARAÚJO, R. S.; ALVES, M. G.; MELO, T. C.; CHRISPIM, Z. M. P.; MENDES, P.; SILVA JÚNIOR, G. C.Water resource management: A comparative evaluation of Brazil, Rio de Janeiro, the European Union, and Portugal. Science of the Total Environment, v. 511, p. 815-828, 2015.

AZEVEDO, D. G.; GOMES, R. L.; MORAES, M. E. B. Estudos da fragmentação da paisagem na definição de áreas prioritárias para a recuperação ambiental da bacia hidrográfica do rio Burahém. Boletim de Geografia, Maringá (PR), v. 34, n. 2, p. 127 144, 2016.

BEHERA, S.; PANDA, R. K. Evaluation of management alternatives for an agricultural watershed in a subhumid subtropical region using a physical process based model. Agriculture, Ecosystems and Environment, v. 113, p. 62-72, 2006.

LANG, S.; BLASCHKE, T. Análise da Paisagem com SIG. Tradução: Hermann Kux, São Paulo: Oficina de Textos, 2009.

BARBIERI, José Carlos. Organizações inovadoras sustentáveis. Caderno de Inovação, v. 3, p. 5-9, 2012.

BOWEN, G. W.; BURGESS, R. L. A quantitative analysis of forest island pattern in selected Ohio landscapes. ORNL Environ. Sciences Div., Publ. ORNL/TM7759, 1981.

BRASIL, Resolução $\mathbf{N}^{\mathbf{0}} . \mathbf{3 0 3}$ de 20 de março de 2002. Dispõe sobre parâmetros, definições e limites de Áreas de Preservação Permanente, 2002. 
CAMPOS, D. O. et al. Zoneamento geohidroecológico da bacia do rio Almada: análise da capacidade de produção de água. In: MORAES, M. E. B.; LORANDI, R. (Org.) Métodos e técnicas de pesquisa em bacias hidrográficas. Ilhéus (BA): Editus, 2016. p. 79-100.

CASATTI, L. Alterações no Código Florestal Brasileiro: impactos potenciais sobre a ictiofauna. BiotaNeotropica, Campinas, v. 10, n. 4, p. 31-34, 2010.

DURIGAN, G; et al. Seleção dos fragmentos prioritários para a criação de unidades de conservação do cerrado no estado de São Paulo. Revista Instituto Florestal, São Paulo, v.18, n. único, p. 23-27, dez, 2006.

FAN, F. M. et al. Sobre o início da rede de drenagem definida a partir dos modelos digitais de elevação. Revista Brasileira de Recursos Hídricos, v. 18, n. 3, p. 241-257, 2013.

FORMAN, R.T.T., GODRON, M. Landscape Ecology. Jonh Wile e Sons: New York, 1986.p.619

IBGE Instituto Brasileiro de Geografia e Estatística, 2018. Estimativa de População. Disponível em: < https://cidades.ibge.gov.br/brasil/ba/itabuna/p anorama> Acesso em 17 de Janeiro de 2019.

LOUZADA, F. L. R. O. et al. Uso de Geotecnologia na determinação de áreas de preservação permanente em topos de morros na micro-região de planejamento da Central
Serrana, ES. In: IX Encontro Latino Americano de Pós-Graduação-EPG. Anais..., 2008.São José dos Campos-SP: UNIVAP, 2008. p. $1-4$

MATTAR, F. N. Pesquisa de marketing. 3.ed. São Paulo: Atlas, 2001.

METZGER, Jean Paul. O Código Florestal tem base científica. Natureza \& Conservação, v. 8, n. 1, p. 1-5, 2010.

MCGARIGAL, K; Marks, B .J. Fragstats: spatial pattern analysis program for quantifying landscape structure. Reference manual, version 2.0. Corvallis, Oregon: For. Sci. Dep. Oregon State University, 1994.

OLIVEIRA, L.T. Caracterização dafragmentação florestal para produção de sementes no entorno capixaba do Parque Nacional do Caparaó.2011.65f. Monografia (Graduação em Engenharia Florestal), Universidade Federal do Espírito Santo, Espírito Santo, 2011.

PMI.Prefeitura Municipal de Itabuna. Dados Municipais: Informações Geográficas. Disponível em: < http://www.itabuna.ba.io.org.br/informacoes Geograficas> Acesso em 17 de Janeiro de 2019.

PIROVANI, B. Daiani et al. Análise espacial de fragmentos florestais na bacia do rio Itapemirim, ES. Revista Árvore, v. 38, n. 2, 2014.

PRODANOV, C.C.; FREITAS, E.C. Metodologia do trabalho científico [recurso eletrônico]: métodos e técnicas da pesquisa 
e do trabalho acadêmico. 2. ed. Novo Hamburgo: Feevale, 2013.277p.

QUEIROZ, P. H. B.; SALES, M. C. L.; SILVA, J. M. O. Indicadores morfométricos como subsidio ao planejamento ambiental em um setor do médio curso da bacia hidrográfica do Rio Pacoti - CE. Revista Equador, v. 3, n. 1, p. 3-24, 2014.

SMANIOTTO, M. Análise ambiental de bacias hidrográficas com base na fragmentação da paisagem: Município de Getúlio Vargas (RS). São Carlos: USFCar, 2007.

SOLLBERG I, Schiavetti A, Moraes MEB. Manejo agrícola no Refúgio de Vida Silvestre de Una: agroflorestas como uma perspectiva de conservação. Revista Árvore, v.38, n.6, 2014.

VIANA W.R.C.C;MORAES M.E.B.Bacia do rio Almada (Bahia):criação de cenários ambientais a partir do diagnóstico da fragmentação florestal.In:Moraes MEB e Lorandi R (Orgs), Métodos e técnicas de pesquisa em bacia hidrógráficas.Ilhéus (BA):Editus,p.35-56,2016.

VOLOTÃO,C.F.S.Trabalho de análise espacial métricas do Fragstats.São José dos Campos : INPE.1998.45 p

Submetido: 05/08/2019

Aprovado: 30/03/2020 